\title{
A restricted view
}

\section{Derek Fordham}

Gender on Ice: American Ideologles of Polar Expeditions. By Lisa Bloom. University of Minnesota: 1993. Pp. 163. \$34.95 (hbk); $\$ 14.94$ (pbk).

Reading National Geographic. By Catherine Lutz and Jane Collins. University of Chicago Press: 1993. Pp. 309. \$59.95 (hbk); \$19.95 (pbk).

"Cook was a liar and a gentleman, Peary was neither", said Peter Freuchen, who knew them both in 1909 when they were squabbling over who, if either, had priority at the North Pole. He probably had a point because Peary was certainly reticent about the Eskimo mistress and several children he had left in the far north. His claim that "the pole is mine" showed similar amnesia about his black companion Henson who stood at his elbow and the Eskimos without whom he could not have reached wherever he was. Peary was indeed a uniquely awful man and it is such episodes that bring him into focus as the main character of Bloom's sincere but at times rather convoluted discourse. The author offers an analysis of the American ideology of polar exploration based on sex and race as the framework for a case study of Peary and the active role of the National Geographic Society (NGS) in promoting and defending him. However, the ease with which Peary found it possible to go his ungentlemanly way, his outrageous arrogance and high selfesteem made him a very difficult protégé.

These books are works of modern social anthropology, both centring on assessments of the NGS. Lutz and Collins go beyond Bloom's case study to examine the cultural issues behind the Society's glossy product - the National Geographic.

Both books deal with the rise of the NGS to power. It was power achieved in the main through its use of the latest advances in photographic techniques. It developed what came to be known as "the language of the photograph". This was a method of satisfying the requirements of the 50 per cent or so of readers who, we are told, explore the world of the Geographic no further than the sumptuous illustrations. By filtering fiction out of its publications it laid claim to the status of a scholarly national institution. It offered its readers only authentic material, claiming, in the words of its editor Wilbur Garrett, "to give the world what it doesn't know it wants yet". It began to vaunt itself as an instrument of government policy, not a mere publisher of a popular magazine. It was the ideal patron and image-maker for the likes of Peary. Peary became a national hero, not because of his personal qualities but as a result of the endorsement of his claims by the NGS.

As for race and sex, the America the NGS reflected in Peary's time was one in which women scarcely featured and black women, with the luckless Henson, not at all, unless it was as a subject for one of the photographs of bare-breasted native maidens, the display of which was a practice the Geographic initiated well in advance of other publications. Such shots are seen by Bloom, Collins and Lutz as

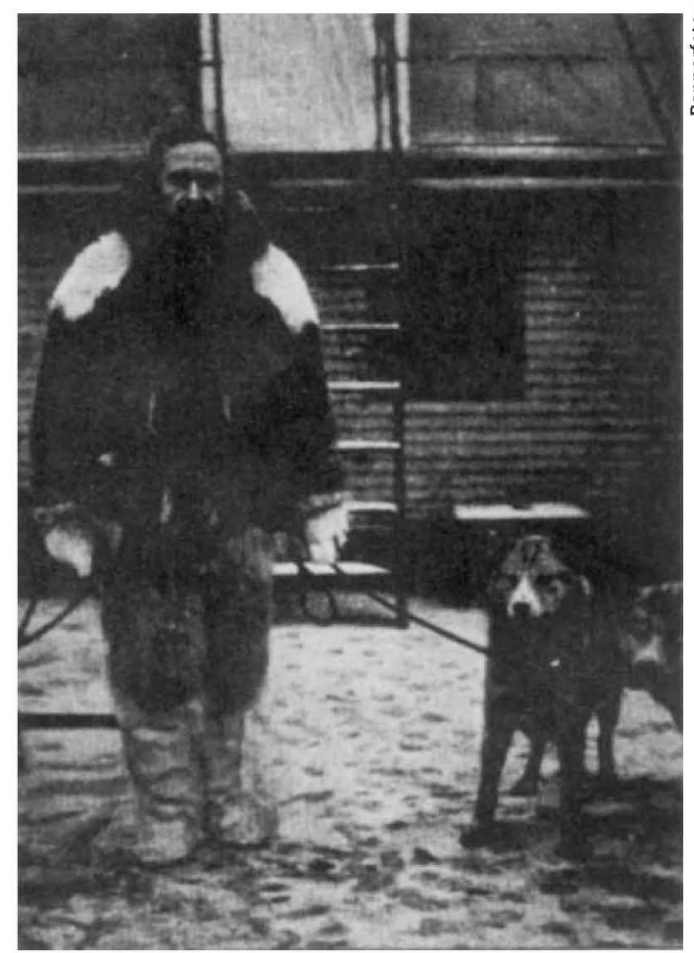

On thin ice? - Peary claimed "the pole is mine".

obliquely emphasizing the essentially white male dominance of the magazine. Such dominance is reflected by Melvin Payne, one-time president of the NGS who, when faced with a photograph of a partially naked Polynesian girl of suspiciously fair complexion said: "We darkened her down to make her look more native, more valid you might say".

The absorbing and lengthy study of anthropologists Lutz and Collins examines the NGS largely through the processes by which the spectacular photographs for which the NGS remains world famous are acquired and used. They also show how "the window on the world and all that is in it" that the NGS claims to open to its readers affords only a restricted view, compatible with the mores of middle-class America and progovernment attitudes. "If the photoUK. grapher didn't find any happy people I'd tell him to go back and find them", was an editorial directive that confirms the Geographic as an instrument of manipulative mass culture. Objectivity comes a poor second to editor Gilbert Grosvenor's 'seven principles' for an acceptable Geographic piece. Principle six specifies that, "only what is of a kindly nature is printed". Set out in 1915, they are still reflected in the sanitized reporting of any potentially uncomfortable issue - and this is the third most popular magazine in the United States.

The complex images of the NGS, set out and criticized by Bloom, are enlarged on by Lutz and Collins who provide a fascinating insight into the intricacies of the photographic processes of the Geographic. They see the NGS's use of photography as symptomatic of an institution purporting to promote humanity and understanding while holding back truly accurate appreciation of non-Western peoples and controversial issues. All this in the interests of a balanced or 'kindly' image. Grosvenor's rules of 1915 still apply -- nowhere more so than on the occasion on which a loincloth did not provide quite enough coverage for the Geographic's sensibility and "shorts to be added by engraver" was pencilled on the proofs.

The Geographic, as these books clearly reveal, often leaves out more than it contains. It is as uniquely American a phenomenon as Peary and apple-pie. It seems likely that few of its many European readers will have perceived the conflicts simmering between the familiar yellow covers that Bloom, Collins and Lutz expose to view. Many will probably find these days that their thoughts on its arrival turn to reassessing the structural implications of the ever-growing stack of those not-to-be-discarded copies in the attic.

For Geographic readers with space in the attic, these books offer stimulating, sometimes over-long insights into the cultural background and decision-making of what, as they reveal, has become a national institution. "Geographical societies would turn into ineffectual adventure clubs without substantial links to science", P. Pauly recently reflected on the position in 1903. For the NGS today, poised on the divide between science and entertainment, things have not changed much.

Derek Fordham is secretary of the Arctic Club, and is at Arctic Camera, 66 Ashburnham Grove, Greenwich, London SE10 8UJ, 